\title{
“Filme de Entrada": o uso do audiovisual como método de pesquisa
}

\author{
Nilson Almino de Freitas ${ }^{1}$ \\ Ana Kélia de Sousa Viana ${ }^{2}$
}

\section{Considerações Iniciais}

O Laboratório das Memórias e das Práticas Cotidianas - LABOME é um arquivo público de documentos especiais, particularmente fotografia, áudio e vídeo ${ }^{3}$. O acervo desse laboratório serve para promover o patrimônio cultural da cidade de Sobral e região metropolitana, pensando as práticas cotidianas como método de produção dessa cultura, de forma processual, muito pouco linear, desterritorializanda, mesmo que tentando territorializar experiências e vivências ${ }^{4}$. Entendemos que a cultura não é uma lista de bens materiais e imateriais estáveis e exclusivos de um grupo, mas uma invenção, se aproximando do sentido que Roy Wagner (2010) confere ao termo. É um processo que ocorre de forma objetiva, uma experiência compartilhada entre agentes diversos. A própria pesquisa é uma construção cultural compartilhada entre pesquisadores e pesquisados. Os agentes envolvidos no processo de pesquisa criam potencialidades, desejos e vivências, provocando afecções múltiplas e aprendizados diversos. A cultura é resultado de processos criados por agentes diversos que se encontram e se desencontram. Cultura é movimento, não lista de elementos materiais e imateriais estáveis.

A perspectiva que trabalhamos admite que a cultura é um aprendizado entre sujeitos, como afirma Wagner (2010) e, acrescentamos, envolvendo objetos como agentes. A estética, a lógica e a imaginação se juntam a cada elemento envolvido em rede nas relações construídas no cotidiano, sejam os elos desta rede constituídos por significados, pessoas, sentimentos e imaterialidades, sejam constituídos por materialidades (coisas, objetos, instrumentos, tecnologias, instituições, etc.).

A “participação” na invenção da cultura não é só do pesquisador e ele não só “observa”. O corpo todo do pesquisador se envolve, inclusive seus afetos, assim como seus interlocutores são ativos e se afetam de alguma forma pela experiência. O pesquisador também não participa da forma

1 Universidade Estadual Vale do Acaraú (UVA).

2 Universidade Estadual Vale do Acaraú (UVA).

3 No campo do arquivismo, documentos especiais se define como aqueles de variadas formas físicas como discos,fitas, disquetes, fotografias, microformas (fichas microfilmadas), slides, filmes, entre outros. Ainda para o arquivismo, este tipo de documento merece tratamento adequado quanto a organização, arranjo e forma armazenamento. Cf.: Lima, 2012.

4 O LABOME pode ser melhor conhecido no site: www.uvanet.br/labome. 
"Filme de Entrada": o uso do audiovisual como método de pesquisa

como um "nativo genérico" 5 o faz. O "nativo” não é uma potência unitária de esforços rotineiros, homogêneos e coletivos de ação e pensamento. O pesquisador traz predisposições culturais muito pouco estáveis que se juntam às predisposições dos agentes individuais que se relacionam, envolvendo o não humano como as coisas, as técnicas, as instituições e o ambiente. São significados que se misturam e provocam uma sinergia de pensamentos e ações. Por ser mistura sinergética, não quer dizer que seja pacífica e consensual. Sempre carrega tensões e conflitos inerentes a relações entre humanos e não humanos, como afirma Latour (2004), superando a falsa oposição entre "sujeito” e “objeto”, entendendo ambos como agentes construtores da sociedade e da cultura, incluindo nessa relação outros elementos que estão no ambiente da relação como agentes.

No caso do pesquisador, ele deveria estar mais aberto para assumir a experimentação como um duplo marginal: nem é mais o mesmo após construir a experiência de pesquisa, nem se transforma em um “nativo”. Neste caso, não é possível inventariar uma cultura e reduzi-la a uma lista de elementos material e imateriais exclusivos, estáveis e "tombá-los" em um livro como se fossem definitivos. De fato, a cultura é um instrumento político e moral que ganha vida na perspectiva de quem a vive, seja ele pesquisador ou pesquisado, incluindo sempre não humanos nesta construção, por meio da invenção (Latour, 2004). De fato, se usa o termo cultura para denominar a situação que se vive para apoderamento dela em busca de sua compreensão e saber como lidar com a experiência da vida cotidiana, buscando controlá-la. Este processo passa por avaliações constantes e revisões de ações e pensamentos. Assim como é resultado de tensões e conflitos abertos para legitimá-la. É por esse motivo que o “tombamento” é importante. Não por ser um ato de preservação de uma história cultural que remete a identidades coletivas estáveis, mas como instrumento político e moral de proteção de práticas e bens que visam solidificar uma visão política do que deve ser entendido como “cultura”.

O vídeo, um dos dispositivos não humano neste processo de invenção da cultura, entra nesse processo como instrumento ativo, no caso das atividades que o envolvem como elo da rede de relações construídas na atividade do trabalho de campo. Mesmo se considerarmos o documentário,

5 As aspas indicam uma concepção dos articulistas de que é impossível encontrarmos um “nativo” puro, exclusivo, isolado, independente e autônomo na sua essência em função das identificações múltiplas presentes em qualquer grupo, o que torna a discussão sobre a identidade coletiva complexa, consistindo em um movimento sinergético e, por vezes, tenso de autoidentificação. Outro movimento que complexifica a ideia de nativo diz respeito aos fluxos e movimentos causados por contatos interculturais. Clifford (1998) desconfia de um tempo onde a ideia de nativo designava realmente uma cultura exclusiva e isolada. Atribui a responsabilidade por esta construção a uma antropologia clássica ao estilo de antropólogos como Malinowski, por exemplo. Nesse caso, este tipo de antropologia ainda carrega resquícios de uma atitude colonialista do pesquisador que entende estar construindo uma relação entre "eu” (pesquisador que sabe) e o "outro”, criando uma cisão radical de humanidades quase exclusiva de um e de "outro” que não se mistura. Desconfiamos desta atitude colonialista e preferimos usar o termo interlocutores em substituição ao de nativo. Por enquanto, o aparecimento entre aspas denota uma postura crítica e desconfiada dos articulistas diante do termo. 
o filme ou o vídeo compartilhado no meio virtual, como expressão de pulsões artísticas ou estéticas do seu autor, de fato, ele, assim, como o texto, também promove uma "educação" de pensamentos. Quanto mais diverso e plural for essa experiência, mais podemos experimentar nossa própria experiência de vida e criar a cultura que queremos. Como afirma Wagner (2010), o estudo da cultura é cultural. Só destacamos aqui o elemento não humano envolvido, que seria o vídeo, sem esquecer que outros elementos materiais e coisas que fazem parte da rede de relações que consolidam a invenção da cultura também são importantes, mesmo na produção do vídeo, como os equipamentos usados, a situação climática, a iluminação, os objetos nos ambientes, dentre outros elementos.

A produção de filmes, a partir desses pressupostos, não é expressão de obras prontas e acabadas que visam documentar a cultura. Eles criam, educam, são instrumentos políticos e morais de afirmação de visões de mundo e de discursos. São também instrumentos de produção compartilhada de experiências que visam valorizar grupos e práticas que entendermos ser merecedores de valorização. No caso aqui analisado, também é instrumento de mediações de planos e atividades conjuntas com os interlocutores.

O caso que aqui merece atenção é o da produção compartilhada com os moradores da periferia de Sobral: o documentário “Arte e Cultura na Periferia - ACP”6 . Tal documentário merece aqui ser lembrado para análise neste prisma de considerar o filme como agente em vários tempos, seja na pré-produção, seja na produção, seja na pós-produção do próprio filme, seja na mediação para se pensar outros projetos. O próprio filme citado já é resultado de outros. O reconhecimento do filme como instrumento político e moral fez-nos pensar neste projeto que já vinha sendo gestado em experiências na periferia de Sobral.

Em 2009, verificando a pouca procura por acervos de entrevistas exclusivas em áudio e vídeo, da natureza que coleciona o LABOME, criamos o programa de extensão Visualidades, que visa usar este acervo a partir de mostras de documentários e exposições de artes visuais, como fonte de reflexão e divulgação de trabalhos de pesquisa com suporte nas linguagens citadas, somando-se às exposições de desenho, pintura e instalações. Cursos de formação nessas linguagens são ofertados, bem como o acervo é disponibilizado e novos documentos são acrescentados com a realização de trabalhos resultantes dos cursos.

6 A pesquisa mais ampla que contempla as atividades descritas tem como título "Visualidades: identificação e registro audiovisual para preservação do patrimônio cultural da cidade de Sobral/CE”, financiada pelo edital PROEXT 2011. Além deste projeto, devemos agradecer ao programa PIBIC/CNPq/UVA pela bolsa concedida à estudante coautora. A FUNCAP também concedeu uma bolsa para o aluno Renato de Sousa Júnior que é codiretor do filme aqui citado durante o texto, “Arte e Cultura na Periferia”. Cf.: https://vimeo.com/147530176. 
Em função do programa Visualidades, no LABOME, do ponto de vista metodológico, a pesquisa videográfica passou a ser um dos focos de atenção da equipe, em função de sua maior adesão para favorecer um diálogo com os interlocutores dos bairros periféricos, o que seria um exemplo de agência que o vídeo promove. A primeira experiência foi com o filme "Sobral no Plural”, dirigido em 2010, por um dos articulistas, em companhia de Paulo Passos de Oliveira ${ }^{7}$. Em 2011, mais três curtas metragens foram produzidos por bolsistas de iniciação científica, orientados pelo Professor Nilson Almino de Freitas. Os filmes inauguraram a série "Bairros de Sobral” que visou valorizar trabalhos que coloquem em evidência as vivências cotidianas e experiências narradas por moradores dos bairros periféricos. Os filmes são os seguintes: "Dom Expedito: cultura, arte e expressão”, , dirigido por Thiago Castro; “Vida e Bairro: Vila União”9, dirigido por Josiany Oliveira; e "Sumaré: história, versões e gerações”"10, dirigido por Daniele do Nascimento. Os três filmes tratam de narrativas sobre questões relacionadas a bairros periféricos de Sobral, por meio de dois enfoques: o das atividades culturais no sentido artístico e o da história local. No ano de 2013 foram produzidos mais dois que, apesar do direcionamento temático, também fazem parte da série "Bairros de Sobral”: "Drama: uma arte”, ${ }^{11}$ de Daniele do Nascimento e "Cultura Quadrilheira”, 12 de Thiago Castro. No ano de 2014, somente um documentário foi produzido para integrar a série: "Lendas Urbanas, Contos e Assombrações", ${ }^{13}$ de Sheila Ramos.

Em 2015, houve uma novidade na proposta inicial de fazer filmes sobre os bairros da periferia da cidade. Novamente, na equipe, os bolsistas de iniciação científica assumiram a direçãogeral. Foi produzido o filme “Arte e Cultura na Periferia - ACP”14. A proposta do filme foi totalmente direcionada pela necessidade de quebrar qualquer regime hegemônico e/ou homogêneo que pense o espaço cultural artístico e a história como unitário, linear, estável e fixo. A cultura, no sentido da atividade artística, como nos demais filmes citados, passou a ser o foco central. Entretanto, para fazê-lo, optou-se pela produção compartilhada com um grupo de jovens do bairro Terrenos Novos que se denomina de Movimento Social FOME. É um grupo que se classifica com orientação ideológica anarquista e atua nos bairros Terrenos Novos, Vila União e Conjunto Habitacional Nova Caiçara, utilizando a arte como forma de mobilização política dos moradores. É

7 Tecnólogo em cinema pela Faculdade Gama Filho, mestre em Comunicação e Cultura pela ECO - UFRJ e doutorando em Artes Visuais pela Universidade Federal de Goiás. Foi professor da área de Antropologia da Universidade Estadual Vale do Acaraú - UVA/Sobral-CE até o ano de 2011.

8 Disponível no Vimeo: https://vimeo.com/81661391.

9 Disponível no Vimeo: https://vimeo.com/82281116.

10 Disponível no Vimeo: https://vimeo.com/84034647.

11 Disponível no Vimeo: http://vimeo.com/78551179.

12 Disponível no Vimeo: http://vimeo.com/76535466.

13 Disponível no Vimeo: http://vimeo.com/87463437.

14 Disponível no Vimeo: https://vimeo.com/147530176. 
um movimento que se coloca contra qualquer forma de organização hierarquizada e não se enquadra como dependente de recursos financeiros do Estado ou da iniciativa privada para realizar suas atividades, dentre as quais Cinema Comunitário, Sopão Comunitário, Batalha de Rap, Grafite, dentre outras.

A produção compartilhada do documentário, de fato, só aconteceu na pós-produção, já que alguns desencontros com os integrantes do Movimento Social FOME não facilitaram a dinâmica de trabalho com eles na pré-produção e produção. Teve-se a ideia inicial de mostrar como a arte é usada nas práticas de diferentes grupos, sua finalidade e relação com uma postura política particular. A relação com o estado, a forma de articular arte e política foram, portanto, o foco central a partir dos moradores dos bairros periféricos que atuam com diferentes artes. Foi feita a produção envolvendo grupos de escola de samba, de rap, grafite, ONG com atividades direcionadas à promoção da arte, teatro, capoeira, dentre outros, nos bairros Terrenos Novos, Vila União, Vila Recanto e Sinhá Saboia. Mostramos todo o material produzido para alguns membros do FOME e solicitamos a decupagem, dentro da proposta inicial do filme. Eles deram o nome do documentário e orientaram a montagem.

A equipe do LABOME considera este filme como um "trabalho de entrada” para novas produções, apesar dele já ter sido resultado de outros trabalhos anteriores. Não se entendeu, nesse trabalho, que seria um filme concluído, mas uma obra que tem como característica a construção de um envolvimento maior com o coletivo citado e a reflexão sobre outros projetos possíveis. No ano de 2016, foram iniciados projetos de interesse deste movimento. Um deles foi o documentário "Rap nas quebradas” 15 , mas naquela modalidade de expressão musical que se mostra mais crítica a determinadas dinâmicas econômicas que colocam o morador do bairro periférico em situação precária no que se refere à qualidade de vida. Outro projeto é sobre o que se denominou de identidade periférica, segundo o movimento. A proposta é conhecer os bairros que atuam a partir da visão que têm sobre estes espaços. Outro é o filme Até o Último Suspiro, dirigido por um dos integrantes do FOME que se tornou bolsista do LABOME, o qual trata do processo de desocupação de moradores de área periférica onde o Estado resolveu realizar um projeto de urbanização, deslocando seus moradores para habitar um conjunto habitacional vertical construído na cidade de Sobral. Esses dois últimos estão sendo gestados em 2018. Algumas questões merecem ser destacadas do ponto de vista da estética, da proposta dos filmes feitos no LABOME, tendo como exemplo o documentário Arte e Cultura na Periferia - ACP.

15 Disponível no Youtube: https://www.youtube.com/watch?v=yACvvyKb980. 


\section{Audiovisual participativo e compartilhado: alguns conceitos, reflexões e apresentação do filme}

No que concerne aos filmes produzidos com apoio do LABOME, talvez se possa dizer que são semelhantes a produções no campo do cinema, classificadas pelo jargão "cinema de guerrilha". No campo da produção cinematográfica, essa expressão classifica obras que não contam com a segurança de uma equipe profissional, não possuem roteiro rígido, se entregam ao desafio de produzir audiovisual sem recursos financeiros e possuem equipe técnica de voluntários ${ }^{16}$. É uma expressão que está relacionada também ao “cinema marginal” do final da década de 1960 e início dos anos 1970, quando a regra era transgredir as orientações e modismos fornecidos pelo circuito comercial.

Outra característica a se acrescentar ao tipo de filme feito no LABOME é a proposta de não se fazer filme de ficção, somente documentário. Nas formações promovidas o grupo tem uma discussão muito introdutória sobre a estética cinematográfica, o que não é suficiente para se obter subsídios teóricos e metodológicos a fim de pensar como se quer classificar uma produção, já que não temos a pretensão de formar cineastas ou técnicos do cinema, apesar de não termos nenhuma oposição a possíveis opções individuais para isso.

De fato, a finalidade principal do laboratório é a produção de fontes documentais em áudio, vídeo e fotografia. O documentário é decorrência de uma necessidade de divulgação desse acervo e uso diferenciado que possa ir além de ser "fonte de consulta”. Nesse caso, a pré-produção, a produção e a pós-produção, se confundem com a pesquisa. Ao ir para o campo, os alunos e pesquisadores o fazem sem saber o que vão encontrar. Ao chegarem lá, descobrem que a filmadora é ativa na construção da relação entre a equipe e o espaço que os interlocutores ocupam. A câmera faz com que tenhamos de nos esforçar para não sermos confundidos com repórteres, apesar de, em alguns momentos, este fato ser motivo de curiosidade e até adesão por parte de algumas pessoas que querem aparecer perante as câmeras. Os acordos são comuns a partir da presença desse instrumento técnico, já que sempre é um desejo corrente do “personagem” ter o arquivo bruto ou se contentar em ter o filme para mostrar o quão é importante para a cidade e para a cultura local.

Por parte dos recursos financeiros, técnicos e da equipe, o fato é que os recursos são poucos, os equipamentos são comprados por meio de financiamento de projetos de pesquisa acadêmica e a

16 Cf.: LEROUX, Liliane. Táticas do cinema de guerrilha da Baixada para transitar entre o popular e o artístico. Revista Polêmica. Rio de Janeiro, UERJ, v. 17, n. 1, 2017. Site: http://www.e-

publicacoes.uerj.br/index.php/polemica/article/view/28300/20344, acessado em dezembro de 2017. 
equipe é de voluntários aprendizes, geralmente bolsistas e alunos que se veem “obrigados”, por suas atividades discentes, a produzir, visando a pesquisa através do filme. São ensinados a pensar a sua produção acadêmica a partir de outras linguagens, inclusive a do audiovisual. São educados a pensar o audiovisual como instrumento, como fonte e como linguagens que expressam concepções de experiências. Discutimos filmes diferentes, semanalmente, especialmente documentários, além de tentarmos aprender sobre os meandros da linguagem.

Portanto, apesar das características apontadas, o leitor pode perceber que as produções não estão muito enquadradas a movimentos no campo da produção cinematográfica e, ao mesmo tempo, possuem algumas peculiaridades desse campo e discussões que podem ser usadas para pensar a relação entre artes visuais e pesquisa acadêmica. As próprias escolhas estéticas e práticas de produção apontam para algumas influências, apesar das discussões sobre isso serem superficiais, se comparadas àquelas presentes dentre os que se formam em cinema, e mais situadas na interface entre a produção acadêmica e a imagem, especialmente na antropologia visual. Isso tendo-se em conta o fato de usarmos posturas corporais nas imagens que aproximam as filmagens à estética do corpo parado, o qual fala estimulado por um entrevistado, o que diferencia nossos documentários daquele que ressalta mais atividades e ações visualizadas na imagem. Alguns filmes nossos, apesar de ainda não serem dominantes no acervo produzido, tendem também a ressaltar esses aspectos da ação, mesclando com falas de corpos parados na cena que expressam suas experiências e concepções.

De fato, os filmes citados possuem algumas características em comum. No campo da Antropologia Visual, existem diferentes tipos de classificação. Comolli (2009) chama a atenção de cinco tipos: o filme de ilustração, que serve para comprovar algo afirmado anteriormente pelo pesquisador; o filme de descrição, que privilegia a descoberta, sugerindo ao público um aprendizado que está sendo descrito durante a filmagem; o filme de expressão, que consiste na crítica social; o filme de explicação, que coloca evidências para tentar proporcionar um efeito de compreensão de temáticas; e o filme intertextual, que concebe a produção como uma relação em rede entre equipe e interlocutores.

No caso aqui analisado - do filme Arte e Cultura na Periferia - ACP, a reflexão sobre o enquadramento em uma destas formas de conceber o filme foi a preocupação central, especialmente quanto ao tipo filme intertextual. Alguns elementos foram motivos de discussão. Um deles é a opção por não usar narrações em off, como se faz no documentário tradicional. A rejeição se deve ao fato de que não se quer crer que o documentário deva ser narrado por uma voz supostamente imparcial e onisciente, o que no jargão do campo do cinema chamam de "voz de Deus". A imagem 
técnica exposta não é uma repercussão de um registro de realidade que pode ser narrado como se fosse a única forma possível de ser documentado, no sentido objetivo e neutro do termo. A equipe não estava preocupada com a autenticidade da realidade registrada no documento visual. É certo que o documentário produz um efeito documentalizante. Mas a equipe entendeu que o documento visual, como já dito, é uma forma de expressão de uma instrução, um conceito, uma posição política e moral, um instrumento de poder e constituição de empoderamento aos sujeitos envolvidos, já que promove uma ideia de autoridade particular àqueles que são reconhecidos como agentes-chaves do que se quer demostrar na montagem da obra, que, no caso, foi o movimento social FOME.

O FOME, apesar de não terem participado ativamente da produção, restringindo a ação à pós-produção, também são personagens do filme. Nesse caso, o filme não é tão diferente do documento escrito. No texto está implícita a mesma lógica documentalizante que devemos desconstruir, para que o leitor tenha uma ideia da forma como ele é produzido, quem é o autor, quais são as orientações teóricas que o fundamentam, assim como as bases sociais, culturais, ideológicas e históricas de sua produção a fim de se entender e compreender essa lógica. A diferença entre o texto e o filme está na ênfase. No filme, não somente a fala, mas o corpo do interlocutor/personagem/performer aparece sendo valorizado na imagem, o que o texto escrito dificulta. Por sua vez, o texto facilita reflexões bastante abstratas e genéricas que o filme não o faz muito. No caso do filme analisado, para valorizar mais ainda o corpo em evidência, evitamos a palavra do “especialista” para não desvalorizar aquelas dos personagens moradores dos bairros que atuam nas atividades exploradas. Nesse caso, o “especialista” é aquele que vive cotidianamente aquelas experiências com a arte naquela especialidade da periferia escolhida.

Entretanto, considerando o olhar como metáfora predominante no campo acadêmico para designar o recurso usual para se fazer pesquisa, apesar de este olhar ser sempre valorizado como "um texto resultado da observação", entende-se aqui que a imagem técnica, mais do que ser resultado da "observação”, tem a potência, suscita o desejo e revela um conceito que se expressa na produção audiovisual. Mais uma vez, vale a pena frisar, não se entende a imagem aqui como sinônimo de "reprodução", ou mesmo “registro" da realidade. A imagem não é uma identificação fiel do acontecimento filmado, nem mesmo uma síntese de uma combinação sintática e semântica que junta pedaços de “realidade” e tem a pretensão de mostrá-la. Aliás, aqui se entende que nem o texto tem esta prerrogativa. No campo da antropologia, muito já se discute sobre a desconstrução da autoridade do pesquisador e do texto em expressar a realidade de um determinado contexto de pesquisa.

Para Clifford (1998), a escrita etnográfica, aquela que tem a pretensão de descrever a 
experiência, de fato é uma tradução desta experiência para a forma textual, resultante de múltiplas subjetividades e, pode-se acrescentar ao pensamento do autor objetividades e constrangimentos políticos. Com a escrita, o pesquisador encena uma estratégia específica de autoridade e tenta transparecer um texto como provedor de verdade. O autor americano duvida da acentuada ênfase no poder de observação do pesquisador, o qual supostamente tem uma postura quase que heroica na tentativa de "desvendar" a realidade. O atalho criado pelo pesquisador é o uso de "poderosas" ferramentas teóricas que pretendem relatar acontecimentos singulares, restritos à experiência do pesquisador no contexto pesquisado, dando a entender que seu texto tem uma significação mais profunda ou supostamente mais geral. Será que o conhecimento tem profundidade?

Ainda segundo Clifford (1998), a pesquisa transparece um caminho que começa pelo trabalho de campo centrado em um intelectual que domina uma determinada linguagem sobre um tipo de iniciação que o leva a um retorno a um texto representacional, escrito por pesquisador, que participa ativamente do processo.

Constata-se aqui que esta discussão é útil para pensar o documentário também, mesmo que entendamos que é uma linguagem diferente da textual. É comum entendermos que o documentário expressa a realidade das coisas que lhe servem como tema. De fato, assim como a escrita etnográfica, o filme é uma tradução da experiência na forma audiovisual, resultante de uma reflexibilidade promovida pela interação entre diferentes sujeitos, espacialidades, temporalidades e constrangimentos políticos e morais, sem deixar de considerar a agência dos objetos, instrumentos, instituições e coisas envolvidas. O documentarista também encena uma estratégia específica de autoridade e tenta transparecer uma suposta verdade factual sobre o tema explorado. A ferramenta do audiovisual, dependendo da forma como é usada, possui um poder acentuado de relatar acontecimentos, dando a impressão de profundidade.

Para Flusser (2002), existe uma diferença entre imagem tradicional, imaginação e a imagem técnica, esta última resultante, especialmente, da fotografia e, consequentemente, do vídeo. Para o autor, a imagem é uma superfície que pretende representar algo. Com a imaginação, o ser humano codifica fenômenos, pensando altura, largura, comprimento e conceituação, sonho ou espírito, transformando-os em símbolos planos, sabendo decodificar a obra em produção, definindo a imagem. A imaginação, portanto, é fazer e decifrar imagens que se apresentam como superfície, mas que, ao serem escaneadas e analisadas pela imaginação, revelam suas dimensões abstraídas.

Como argumenta Flusser (2002), a escrita, com o tempo, passou a ser foco de “textolatria”, dando a entender que ela pode ser fiel à realidade. Este movimento teve repercussões na imagem técnica, quando ela surge no século XIX, criando-se a "idolatria”. Para o autor, com esta “idolatria”, 
a imagem técnica, especialmente a da fotografia e do audiovisual, produz uma representação que se interpõe entre o mundo e o ser humano, criando o "mundo”. As pessoas passam a viver em função da imagem com o advento da fotografia e, logo após, o filme. O mundo passa a ser entendido como um conjunto de cenas, a partir da percepção de que a realidade reflete imagens e vice-versa. O ser humano esquece que a imagem técnica é um instrumento para orientá-lo no mundo, fazendo com que se perca a capacidade de decifrar as dimensões abstraídas dela própria. Esquece também que a imagem técnica é imagem de terceira ordem, pois abstrai uma das dimensões da imagem tradicional para resultar em textos visuais. Depois, reconstitui a dimensão abstraída a fim de produzir imagens. Portanto, de fato, as imagens técnicas imaginam textos, concebem imagens que imaginam o mundo. O problema é quando o observador entende a imagem técnica como janela e não como imagem.

Entendendo a imagem técnica como conceito a ser decifrado, pode-se crer que ela é um instrumento potente para produção científica, já que o processo de pesquisa se faz também como na produção textual: fruto da interação em rede com vários elementos que se envolvem na experiência do pesquisador que, por sua vez, usa de sua imaginação para produção do texto ou documento audiovisual ou fotográfico que não são a significação do mundo. Os textos são imagens expressas de forma linear, definindo conceitos e ideias. O deciframento do texto revela imagens que significam conceitos. A escrita, portanto, para Flusser (2002) é metacódigo da imagem. A imagem técnica, por sua vez, tem a capacidade de ir além de ilustrar o texto. Ela tem o poder de remagicizálo, articulando imaginação e conceituação. A relação entre imagem técnica e texto promove a criatividade, entendendo que a diferença está na ênfase de cada linguagem. Enquanto a escrita estimula a imaginação por abstrações poderosas, a foto e o filme estimulam com efeitos visuais e corporais também poderosos.

Como diz Flusser (2002), os textos podem ser metacódigos de imagens, mas determinadas imagens podem ser metacódigos de textos. Pensando nessa lógica é que a pesquisa videográfica se justifica como tendo o mesmo valor que qualquer outra forma de método e de divulgação científica, resguardando sua especificidade e, ao mesmo tempo, contribuindo para reflexibilidade própria e necessária da atividade de pesquisa. Em função da “idolatria”, também ajuda no processo de comunicação com interlocutores que preferem a imagem técnica ao texto como forma de reflexão, o que é muito comum. Foi muito comum notarmos a diferença, já na abordagem. Dizer que veio fazer pesquisa e tornar esta experiência em um texto, não é a mesma coisa de chegar e informar que o interlocutor vai ser personagem de um filme. Lógico que a suposta facilidade em entrar no espaço do interlocutor com uma filmadora vai variar de contexto para contexto. Em alguns lugares facilita, em outro dificulta. Depende muito de outras variáveis sociais envolvidas e do tipo de internalidade 
que o pesquisador já possui no grupo pesquisado.

Entretanto, trabalhar com a pesquisa videográfica tem seus limites e possibilidades. Não podemos dizer que o registro em diário de campo, geralmente uma primeira experiência textual do pesquisador ao voltar da atividade de campo, tem a mesma potencialidade como fonte de reflexibilidade do que o vídeo gravado. Geralmente conseguimos perceber e pensar muito mais quando escrevemos sobre a experiência de campo. O registro do diário de campo é mais rico. Por outro lado, o registro filmado permite uma maior interlocução entre os "personagens” e equipe envolvidos, promovendo uma autoria compartilhada, mesmo que o pesquisador não queira. Os corpos da equipe e dos personagens, articulados com os instrumentos, meio ambiente e coisas envolvidas, formam uma sinergia de afetos que produzem imagens que nem sempre são as mesmas previstas pelo diretor. Há uma espécie de colaboração que não é possível ser realizada no trabalho textual quando se está produzido no diário de campo, exceto aquela do momento da experiência que afeta o pesquisador de alguma forma, estimulando a construção de certos códigos de entendimento desta experiência que não estavam previstos após o aprendizado da pesquisa. Mas, no momento da escrita final, o pesquisador está solitário.

A vantagem que mais interessa à equipe que compõe o LABOME é a de que o filme promove diálogo com um público mais amplo do que com os pares da academia. Não só na produção, mas na divulgação também. O exemplo é o que promove o Visualidades, projeto de extensão que organiza mostras descentralizadas de artes visuais (documentário, fotografia, desenho, pintura e instalações). Os filmes que produzimos entram nesta mostra que acontece em escolas de ensino fundamental e médio, equipamentos sociais das prefeituras, como o Centro de Referência da Assistência Social - CRAS de alguns bairros, ONG's, dentre outras instituições e locais das periferias das cidades envolvidas. Nesses momentos percebemos o quanto os filmes chamam as pessoas para o diálogo, propiciando um debate sobre suas vidas, especialmente porque se veem nas imagens ${ }^{17}$, mesmo que sejam documentários.

É importante ressaltar que na produção do filme, especialmente no caso em que é realizado com maior participação dos interlocutores do trabalho de pesquisa, o excesso, a velocidade, a tecnociência fazem com que a imaginação seja canalizada para fins institucionalizados, padronizados, fabricados e expostos a variações e desejos efêmeros. A crença em algo sólido e estável está diluída nesse movimento. Ela também se torna efêmera, negociável e passível de trocas simbólicas “comercializadas” no cotidiano das relações, criando identidades possível e desejadas. As sensações, as pulsões, os desejos passam a ser vítimas da aparência, do brilho da superfície e do

17 Sobre o Visualidades, Cf. FREITAS (2017). 
fugaz. Logicamente, todo esse movimento passa por mediações contextuais. Ele não é homogêneo. Porém, por sua causa, é cada vez mais difícil acreditar, com convicção, se determinada manifestação de indivíduos ou de grupos sociais é crença ou fantasia em relação ao discurso sobre suas identidades.

Gonçalves (2009), inspirado em Deleuze, chama a atenção quanto a particularidade da produção fílmica, onde a autoimagem produzida pelo personagem, mesmo no documentário, é acentuada pelo seu devir-imagem. Para Deleuze (1997), o devir não faz muito sentido no registro do “ser” substantivo. É um bloco de coexistência plural de afecções entre blocos de movimentos que se espalham de tal forma que não permitem definição de fronteiras fixas. Esta definição caminha contra a ideia de que a identidade produzida pelo personagem é uma soma de partes da experiência social e cultural ou que ele produz semelhança e afinidade com algo rígido que o identifica. De fato, os diferentes blocos de movimento, onde só podemos identificar, e, mesmo assim parcialmente, alguns, provem encontros e “choques” de valores e práticas. São repostas contextuais diante da sociabilidade construída no cotidiano da relação entre os diferentes agentes que produzem ou concorrem pela identificação que cada um tenta criar. A identidade criada pelo personagem é um desejo. Deleuze (1997) entende o conceito de desejo como agenciamento de um conjunto de elementos que constituem o contexto do objeto supostamente referente. Não se deseja uma identidade, mas uma série de elementos que formam um conjunto relativo ao lugar, à posição, ao interesse e à imagem que estão “ao redor” do “ser” desejado e o reforçam.

A autorepresentação é subversiva de uma verdade constituída sobre si, inventando, consequentemente, sua identificação enquanto pertencente a um coletivo. A fabulação é uma agressão à rigidez, pois a desestabiliza, faz pensar e desterritorializa. Ao mesmo tempo, cria o que Gonçalvez (2009), via Deleuze, chama de intercessores, usados pelos personagens em busca de uma reconciliação com a valorização de si como protagonista. Ele se movimenta para intervir nas hierarquias que parecem sólidas, produz cruzamentos, subverte fronteiras, faz aquele que o vê pensar, o desestabilizando. Para alcançar tal efeito, como lembra o autor, usa da ideia de sinceridade a qual busca dar uma essencialidade, borrando as fronteiras entre o ficcional e o não ficcional de sua “iconicidade pessoalizante”.

Por isso, fazemos a opção pela imagem técnica que estimula imagens, feita de influências também exteriores e múltiplas. A imaginação, por mais que se esforce, não consegue acompanhar de perto a proliferação exaustiva e excessiva de imagens, que, por sua vez, mostram novos horizontes, em todo o tempo realimentando a imaginação. Nesse caso, não é possível dizer que a imagem técnica dá conta de tudo, tornando-se muito mais uma concepção provisória. 
Vale a pena agora pensarmos com mais detalhes o exemplo concreto do filme ACP a fim de entendermos melhor esta postura na sua produção e como ele pode servir para várias coisas, além de expressão resultante de uma pesquisa específica.

\section{O filme}

No caso do filme “Arte e Cultura na Periferia - ACP”, inicia-se a narrativa com o clipe de imagens, intercalando apresentações artísticas com paisagens dos bairros em foco: Sinhá Saboia, Terrenos Novos, Santa Casa e Vila União. A trilha sonora inicial é do grupo de rap Expressão Cruel, organizado por moradores da Vila União. Alguns de seus membros são do movimento social FOME. A primeira parte consiste em abordar a expressão artística e sua finalidade, segundo os personagens apresentados que atuam em áreas diferentes. A primeira expressão artística abordada é o grafite com imagens também intercaladas de depoimento de Tiaguinho e oficinas de pintura em muros, realizadas por ele. Ele ressalta a capacidade que esta atividade possui em mobilizar, criar laços solidários, inclusive resolvendo problemas relacionados a usuários de drogas que trocam os entorpecentes pela expressão de sua arte no muro. Esta narrativa de Tiaguinho passa a fazer a crítica a alguns projetos educacionais pensados nos bancos universitários que não geram o mesmo efeito.

Logo após, aparece Andrine, atriz de teatro, ressaltando que, ao iniciar sua atuação neste campo artístico, já se envolvia com a política, ainda que sem perceber. Quanto às suas escolhas preferenciais, entre peças com temas infantis, por exemplo, e outras com temas mais polêmicos, ela confessa que preferia a segunda opção, o que acabou orientando o grupo de que fazia parte, no Instituto Teias da Juventude - ITJ ${ }^{18}$, pela mesma preferência.

O Senhor Chico, presidente da escola de samba Unidos da Vila União, é o próximo personagem a ser apresentado pelo filme. Ele chama à atenção que, ao atuar como líder comunitário, tudo que se faz em benefício do "povo” redunda em que se seja mais conhecido. E a atuação na escola de samba o faz mais conhecido ainda. Sua narrativa quer afirmar o seu reconhecimento na comunidade, o que estimula o seu trabalho para o “povo”. Quando indagado sobre o envolvimento da comunidade na escola de samba, afirma que o engajamento é grande e, além disso, contribui para que o jovem não se envolva com o mundo das drogas. O presidente da Estação Primeira do Sinhá Saboia reforça a ideia de doação à arte e ao “povo”, ressaltando que só faz arte quem tem amor, pois as dificuldades são muitas. No depoimento de ambos, aparece muito

18 ONG que será abordada no filme. 
mais a dimensão da solidariedade e do culto à arte como ato heroico, desprendido e desinteressado do ponto de vista financeiro, do que sua dimensão de mobilização política. No máximo, a mobilização visa à resolução de problemas sociais, quase como um ato assistencial.

Mestre Bob ressalta a interdisciplinaridade da Capoeira como arte, envolvendo a música, a dança, a luta, o esporte e competição, preparando para a vida, via disciplina. Episódio de sua história pessoal é lembrado quando, ao levar um projeto de capoeira à Secretaria de Cultura do Município, a pessoa que o recebeu ressaltou a dimensão interdisciplinar da Capoeira. Entretanto, como vivemos no "mundo capitalista”, como ele lembra, acabou não tendo apoio. Compreendemos que, com esta afirmação, o narrador quis dizer que a capoeira não traz lucro. Portanto, não vale a pena ser financiada. No bairro, entende-se que a atuação desta arte é muito importante, pois tem como foco crianças com “risco social” que terão apoio para se tornar "bons cidadãos”. A dimensão da assistência também está presente no seu discurso. Ao mesmo tempo, acompanha um lamento por ser o lucro o foco prioritário de nossa sociedade, impedindo um maior apoio à sua arte.

A segunda parte apresenta instituições e coletivos que atuam com cultura nos bairros da periferia. A primeira é o Instituto Teias da Juventude - ITJ. Chiquinho, diretor da instituição, apresenta a entidade e informa sobre seu foco central, que é a atividade artística entre jovens de vários bairros da periferia de Sobral, visando ressignificar sonhos, valores e construir projetos de vida nestes jovens, sobretudo por meio do teatro, da música e da dança. A proposta é construir novos caminhos para eles. O protagonismo dos jovens é estimulado, aproveitando suas capacidades criativas. Na entrevista, ele informou que 180 jovens participavam das atividades do projeto Vida nas Teias da Cultura, o principal projeto do ITJ.

Na cena seguinte, Márcio Tibúrcio, da Sociedade de Apoio à Família Sobralense - SAFS, atuante no bairro da Santa Casa, apresenta o método Monitoramento Jovem de Políticas Públicas MJPOP, criado pela Visão Mundial, ONG brasileira vinculada à Igreja Católica. A proposta é trabalhar o empoderamento dos jovens no monitoramento de políticas públicas, na sua comunidade. Durante a explicação, acontece um tiroteio no bairro, provocando confusão dentre os integrantes da reunião, que fogem para suas casas.

O tiroteio citado antecede o depoimento de Leandrinho, MC do bairro Vila União. Ele lembra que, desde pequeno, vê a ação, da polícia no seu bairro e a considera opressiva. Tal costume, o qual foi se banalizando na vida dele, acabou repercutindo nas suas brincadeiras de infância, representando a disputa entre polícia e ladrão. Um clipe do grupo Expressão Cruel, com título "Infância” é introduzido no filme. Conta uma história semelhante a que lembra Leandrinho, no que se refere à banalização da violência. Ambos, Leandrinho e Expressão Cruel, são integrantes do 
movimento social FOME, coletivo que passa a ser apresentado por Renan no filme. Renan também narra suas vivências na infância nos bairros da periferia, o que o fez criar um sentimento de revolta contra o abandono destes espaços pelo poder público. É exatamente esta revolta que gera o FOME. Informa que preferem ter um caráter mais libertário e autônomo. A proposta é construir juntos com os moradores uma vida melhor, sem vanguardas, sem membros entendidos como líderes e sem hierarquia.

A trajetória de pobreza também faz parte da narrativa do mestre Bob. A capoeira surge para ele como uma necessidade de um povo, e, por isso, ele começou nesta arte. Fala que não tinha alimentação em casa, e sua mãe descobriu o projeto na FEBEMCE e, dentre as opções ofertadas, escolheu a capoeira, meio forçado por ela.

Seu Chico volta a aparecer no filme, mostrando como a comunidade participa da escola de samba. Ele chama à atenção a importância do voluntariado quanto à mobilização das pessoas. Informa que sua atuação não se resume à apresentação na época do carnaval. A escola de samba oferta cursos de formação de percussão, corte de cabelo, dentre outros. O apoio financeiro é dado pela Prefeitura de Sobral. Seu depoimento sobre a necessidade da relação com o poder público é reforçado pelo presidente da escola de samba do bairro Sinhá Saboia. Segundo ele, se não tiver este apoio da prefeitura, ninguém faz o carnaval por conta própria.

Tiaguinho aparece fazendo o contraponto, ressaltando que o poder público muito mais atrapalha do que ajuda. Lembra quando estava "fazendo um muro" e foi tachado de "vândalo” e “marginal” por fazer aquilo. Representantes da prefeitura cobriram sua arte, feita com a "grana” do próprio bolso. O artista, que é pai de família, desempregado, vivendo de "bico", faz a arte e o poder público vai lá e apaga. Ele se coloca como independente, pois não pede nada, nem vai à Secretaria de Cultura pedir ajuda. Até já foi, mas sempre tem “as portas fechadas”. Não é por isso que deixa de fazer sua arte. Ele consegue tinta vencida, material ruim, mas não deixa de estar na rua fazendo o trabalho.

Chiquinho volta a informar de suas parcerias em programas e projetos, os quais, desde 2007, eram executados pelo Conselho Municipal de Direitos da Criança e do Adolescente, com apoio do Fundo Municipal de Direitos da Criança e do Adolescente e, posteriormente, passa a ser do ITJ. Nos últimos quatro anos foi financiado pela Lei Rouanet (Lei $n^{\circ}$ 8.313/1991 - Lei Ordinária, de 23/12/1991), por meio do Instituto Votarantim. A proposta é discutir como a juventude pode ocupar os espaços urbanos. Para ele, é importante entender que os equipamentos públicos são do povo.

Talisson, também do movimento social FOME, aparece falando de sua multiformação no campo artístico. O breack fica em destaque na sua fala e na cena que aparece na sequência. Fala do 
grafite também, mas frisa que a manifestação cultural não depende de “prefeito”. Após a cena que exibe a prática do grafite, Renan chama a atenção da contradição que existe dentro da universidade que não “cola” com o pessoal da periferia, apesar de se falar muito de mobilização popular. Para ele, são poucas as pessoas que têm a coragem de pular os muros da universidade e estarem lá conversando com os moradores dos bairros periféricos. De fato, o que eles fazem, como movimento social, é o contrário: mostram que ele também tem a sua forma de expressão: a “fome” é sua resistência. Leandrinho aparece com exemplo, lembrando que foi membro de gangue, ex-usuário de drogas, mas resgatado deste submundo pelo rap. Um clipe dele, com o título “O crime não compensa” aparece no filme, com tema que expressa sua afirmação. O final do filme mostra a quarta edição do evento RAP no Beco, organizado pelo FOME e outros jovens interessados em expressar sua arte falando da periferia. A proposta agora é amarrar as pontas soltas.

\section{Considerações finais: amarrando algumas pontas soltas sobre o "filme de entrada"}

Entendemos que o filme descrito não representa um trabalho concluído de uma tentativa nossa de produção compartilhada, mas um “documentário de entrada”. Não seria ainda o documentário final a ser produzido com moradores da periferia da cidade, mas uma forma de aproximação. Uma aproximação onde finalmente foi formalizado um compromisso entre o FOME e o LABOME para sua produção, apesar de outros filmes já estarem relacionados a esta tentativa de trabalhar com os moradores da periferia como protagonistas do filme e da produção. Nesse caso, a produção videográfica seria um método de pesquisa e uma forma de inserção no espaço geográfico territorializado por aqueles que queremos como companheiros em uma empreitada pelos meandros da cidade, especialmente a periferia. Não foram escolhas baseadas em optar por “representantes” da periferia, mas aqueles que se alinham a determinadas concepções que entendemos serem de nosso interesse.

Não queríamos fazer com que os moradores se reconhecessem no filme ou fazer dele uma forma de constituição de afetos e afinidades. Pelo contrário, queríamos ser reconhecidos e, ao mesmo tempo, mostrar nosso interesse por superar qualquer tipo de diferença que pudesse ser uma barreira para nossa relação em novas produções compartilhadas. Claro que este interesse está carregado de uma desconfiança mútua, já que superar barreiras não se consegue sem grandes dificuldades. Algumas delas intransponíveis se depender exclusivamente de nosso esforço individual, como as diferenças de classe e de posição social.

Nesse caso, o devir-imagem não se aplicaria somente ao esforço dos personagens em criar 
suas identificações no filme. O próprio filme é um devir, ou, como prefere MacDougall (2009), é transcultural. Isso porque a construção resultante da relação entre as diferentes agências não tem o controle total das partes envolvidas e sofrem influências que vão além das pessoas, como as exercidas pelas instituições, tecnologias e acontecimentos imprevistos. Nem os "personagens” se sentem completamente representados, nem os membros da equipe, apesar destes serem os responsáveis pela montagem final.

No caso do ACP, chamamos alguns “personagens” para a montagem. A escolha tinha relação com os interesses e afinidades políticas e ideológicas da equipe com o FOME, como já dito, movimento social já mencionado aqui. Verificamos que, de forma compartilhada, a escolha do título e das imagens que iam compor cada sequência criou uma narrativa que fala de uma etnografia da duração (Eckert e Rocha, 2013), que compreende o tempo e, incluímos aqui o espaço, como construções pouco estáveis, criativas e sobrepostas que tentam falar de uma padronização da cultura e relação com o campo político, mas que mostra também tensões e conflitos que tornam plurais estas tentativas de criação de padrões, formando um mosaico em movimento.

Cada narrativa não pode ser entendida como representação fiel de um patrimônio cultural homogêneo que fala desta relação entre expressão artística e política. Pelo contrário, cada morador da periferia que aparece no filme inventa formas de sociabilidade e idealizações da vida de forma vertiginosa, formando um movimento ambíguo de tentativa de padronização e desencaixes que produzem uma cidade vivida de forma multiforme. Para Eckert e Rocha (2013), assim como para os articulistas, este movimento, que, aparentemente, é caótico, não é negativo. É um meio de libertação de prisões morais sobre como se deve praticar o tempo e o espaço na cidade.

A etnografia da duração produzida exige do pesquisador uma lógica também errante, cambiante, que valorize o instante e reveja a ideia de que o filme expressa um resultado final de uma produção audiovisual. No caso de ACP, de fato, é o início que, por sua vez, é resultado de um processo anterior. Talvez o início de uma nova etapa, onde a formalização da produção compartilhada se fez visível. A lógica a ser seguida é meio incerta depois de iniciado este processo. Um dos jovens integrantes do movimento FOME passou a ser um dos bolsistas do LABOME, como já dito, e os projetos pensados durante e após o filme ACP, ainda estão em andamento e revistos todo tempo diante das incertezas da vida de pesquisadores interessados em acompanhar o cotidiano das periferias da cidade.

A duração da relação entre o pesquisador e o pesquisado não segue uma lógica linear e racional. É uma luta constante com e contra o tempo, o que promove o movimento. Como diria Veyne (1998), as narrativas produzidas no processo de pesquisa são muito pouco científicas e são 
acompanhadas de escolhas convenientes que têm pouca importância relacional. É um drama, no sentido teatral do termo, que não quer se apresentar enquanto tal, que passa de um plano temporal para outros procurando um sentido narrativo. No caso analisado aqui, esse drama não se resume ao processo de produção do filme ACP. Ele não tem também um início, meio e fim. Se amarra e se solta a outros projetos e relações que fogem ao campo restrito de produção do filme citado. É um cruzamento de fatos e itinerários temporais e espaciais previsíveis e, ao mesmo tempo, imprevisíveis que tentamos organizar com os recursos que temos.

O filme ACP, portanto, é uma tradução padronizada de uma experiência social e cultural possível, assim como um poder e tentativa de controle de uma situação sobre experiências compartilhadas que foram desenvolvidas e que estão em gestão possível de se pensar e fazer. Quando falamos de um “filme de entrada”, portanto, não estamos falando, na verdade, só de um início, mas de um entremeio de relações que podem gerar algumas coisas que vão além do planejado, o que é típico de qualquer projeto compartilhado. Algumas coisas já estão sendo feitas, como os projetos já citados sobre rap, sobre desocupação e visão sobre a periferia a partir de seus moradores.

Talvez o filme citado se aproxime muito pouco das ideias inovadores de Jean Rouch no que se refere ao cinema verdade do ponto de vista da estética escolhida ${ }^{19}$. Mas, como ele, a partir de nosso filme, podemos pensar em outras experiências. A diferença talvez seja somente esta das experiências não aparecerem na imagem produzida, como faz Rouch, portanto, não estarem presentes na narrativa visual. Mas sabemos que, nem mesmo no caso dos filmes de Rouch, tudo que foi compartilhado entre humanos e não humanos, apareceu no processo de produção, já que a imagem não corresponde a um enquadramento de $360^{\circ}$, e houve escolhas estéticas e cortes, como em todo filme, ou seja, houve montagem resultante de uma seleção, ordenação e ajustamento dos planos a fim de alcançar o resultado desejado em termos narrativos, informativos, dramáticos, visuais, experimentais de interesse do cineasta, como toda obra fílmica.

No nosso caso, não nos esforçamos para mostrar uma produção compartilhada onde o diretor aparece em diálogo com os personagens. O esforço principal estava fora do filme, contemplando interesses maiores que ele, embasado em escolhas epistemológicas que negam um tipo de pesquisa que se sustente por práticas colonialistas. Palavras como “outro”, “informante”, dentre outras clássicas do jargão antropológico, tentamos substituir por outras como “nós” e “interlocutor”, por exemplo. O “outro” não é tão outro assim quando pensamos nas relações sociais

19 Nos referimos aqui ao filme “Crônicas de um Verão”, de Jean Roch e Edgar Morrin, produzido em 1960. Sobre ele, podemos ler o artigo de Hikiji (2013), dentre vários outros já produzidos sobre ele e sua obra. Como diz a autora, ele inspira e provoca. 
estabelecidas no trabalho de campo e na produção de obras a serem publicadas como "resultados" desta relação. Nem mesmo são objetos inertes e detentores de rotinas estáveis nas suas vivências cotidianas. Os personagens, o ambiente, os instrumentos, dentre outros agentes subjetivos e objetivos, são comparsas, parceiros, não no sentido da afinidade e identificação radical, mas na busca por uma “alteridade mínima”, como diria Abreu (2008), baseada em uma tipologia criada por Mariza Peirano, aplicando sua reflexão epistemológica à nossa situação aqui descrita. Nesse caso, nossos parceiros produziram conosco, sem pensarmos inocentemente que, com isso, estaríamos superando nossas diferentes sociais e culturais. Tudo se misturou e criou algo que não é mais o que esperávamos, nem é o que nossos interlocutores esperavam. É subversivo em todos os sentidos, mas por que isso é ruim? Resta-nos acompanhar este movimento e colaborar com o seu fluxo em tensão com todos os demais agentes envolvidos.

Referências

ABREU, Regina. Tal antropologia, qual museu?. Rev. do Museu de Arqueologia e Etnologia, São Paulo, Suplemento 7, 2008, p. 121-143.

CLIFFORD, James. Sobre a alegoria etnográfica. in.: A experiência etnográfica: Antropologia e literatura no século XX. Rio de Janeiro:UFRJ, 1998.

CLIFFORD, James. A experiência etnográfica. Rio de Janeiro: UFRJ ,1998.

COMOLLI, Annie. "Elementos de método em antropologia fílmica". In.: FREIRE, Marcius LOURDOU, Philippe (orgs.). Descrever o visível: cinema documentário e antropologia fílmica. São Paulo: Estação Liberdade, 2009, pg.23-52.

ECKERT, Cornélia e ROCHA, Ana Luiza Carvalho da. Etnografia da duração: antropologia das memórias coletivas em coleções etnográficas. Porto Alegre, Editora Marcavisual, 2013.

DELEUZE, Gilles \& GUATTARI, Félix. “Devir-intenso, devir-animal, devir-imperceptível”. in.: Mil platôs: capitalismo e esquizofrenia. vol.4, Rio de Janeiro, Editora 34, 1997

FREITAS, Nilson Almino de. Visualidades: Restituição e inserção social. Iluminuras. NUPECS/LAS/PPGAS/IFCH/UFRGS, v. 18, n. 45, 2017.

HIKIJI, Rose Satiko. Rouch compartilhado: premonições e provocações para uma antropologia contemporânea. Iluminuras, Porto Alegre, v.14, n.32, jan./jun. 2013, p.113-122.

FLUSSER, Vilém. Filosofia da Caixa Preta - Ensaios para uma futura filosofia da Fotografia. Rio 
de Janeiro: Relume Dumará, 2002.

GONÇALVES, Marco Antônio e HEAD, Scott. Confabulações da Alteridade: imagens dos outros (e) de si mesmos. in.: GONÇALVES, Marco Antônio e HEAD, Scott (Org.). Devires Imagéticos: $a$ etnografia, o outro e suas imagens. Rio de Janeiro: 7letras, 2009.

WAGNER, Roy. A invenção da cultura. São Paulo, COSACNAIFY, 2010.

LATOUR, Bruno. Politicas da natureza: como fazer ci ncia na democracia. Bauru, SP: EDUSC, 2004.

LIMA, Fábio Lúcio Moreira. Apostila de noções de técnicas de arquivo. Disponível no site http://www.fortium.com.br/blog/material/arquivologia.pdf, acessado dia 29 de julho de 2012.

MACDOUGALL, David. Cinema Transcultural. Antípoda, nº 9, julho-dezembro de 2009, p.47- 88. VEYNE, Paul. Como se escreve a história e Foucault revoluciona a história. Brasília: UNB, 1998.

Recebido 23/04/2019

Aprovado 28/05/2019 